\title{
Professor Emérito Jorge Ponciano Ribeiro
}

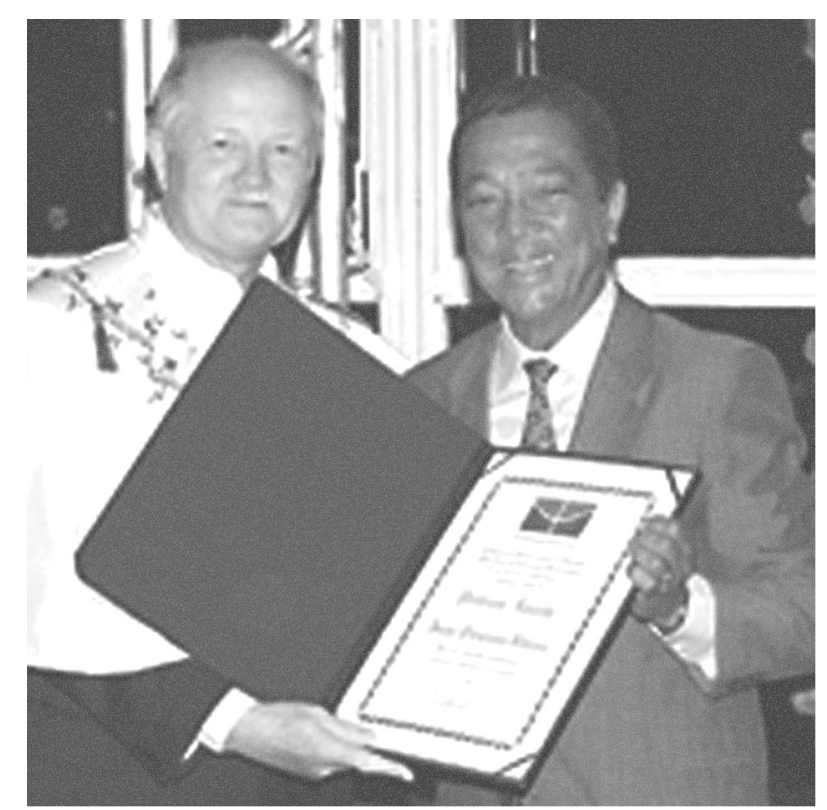

Figura 1. Professor Emérito Jorge Ponciano Ribeiro recebendo a premiação das mãos do reitor da Universidade de Brasília, Professor Timothy Mulholland.

Fonte:_http://www.unb.br/acs/unbagencia/imagens/ag0306-66f3.jpg

\section{Relato da Trajetória do Professor Jorge Ponciano Ribeiro ${ }^{1}$}

\section{Dados biográficos}

O Prof. Jorge Ponciano Ribeiro nasceu no dia 10 de fevereiro de 1933 na cidade de Bocaíuva, Minas Gerais. É filho de José Ponciano Ribeiro e de Alzira Ponciano Ribeiro.

Jorge Ponciano iniciou o curso de Filosofia Pura em 1952 e graduou-se em 1955. Quatro anos depois, em 1959, graduou-se em Teologia. Ambos os cursos foram feitos no Seminário Provincial de Diamantina, MG. Tornou-se padre e foi Monsenhor, exercendo suas atividades religiosas na região norte do Estado de Minas Gerais. Deixou posteriormente a vida religiosa, sem abandonar, contudo, o compromisso em aprofundar e contribuir para o conhecimento da condição humana.

Ao longo de sua vida o Prof. Jorge Ponciano Ribeiro recebeu diversos títulos e homenagens em reconhecimento à sua atuação. Em 1973 recebeu da Câmara Municipal o título de Cidadão Benemérito da Cidade de Porteirinha. Em 1977 foi agraciado com o título de Sócio Honorário da Academia Montesclarense de Letras. Em 2002 recebe placa e certificado de reconhecimento por sua contribuição ao Instituto de Psicologia da Universidade de Brasília. Recebeu ainda

1 Texto produzido pelo Prof. Marcelo Tavares do Departamento de Psicologia Clínica como parte do processo de proposta de outorga de título de Professor Emérito ao Professor Jorge Ponciano Ribeiro. A editora agradece ao Departamento pela cessão deste texto para publicação. o título de Cidadão Honorário de Brasília, outorgado pela Câmara Distrital, por sua contribuição à área da educação no Distrito Federal.

\section{Formação na área da psicologia}

No ano de 1970, o Prof. Jorge Ponciano recebe o Diploma de Qualificação em Psicologia pela Ponteficia Università Salesiana - PUS (Roma, Itália), e inicia seu curso de Mestrado em Psicologia. O título de mestre foi obtido em 1972 com o trabalho intitulado "Introdução ao Pensamento Psicoterapêutico de Siegmund Heinrich Foulkes".

Concomitante ao curso de mestrado, o Prof. Jorge Ponciano realizou dois cursos de especialização, sendo um em Psiquiatria e outro em Neurofisiologia Clínica na Universidade Católica Del Sacro Cuore - UCSC (Itália). Em 1972 ele inicia o curso de doutorado, também na Ponteficia Università Salesiana - PUS, na Itália, o qual é concluído em 1975.

Retornando ao Brasil no mesmo ano, inicia no Instituto Brasileiro de Psicologia e Educação - IBPE o curso de Especialização em Psicoterapia de Grupo, concluído em 1976. Durante o biênio de 1978-1980 cursa no Center for Studies of the Person-CSP (EUA) o curso de especialização em Gestalt Terapia. Estas duas áreas se tornaram, a partir de então, o foco da atuação do Prof. Jorge Ponciano Ribeiro. 
O Prof. Jorge Ponciano fez dois pós-doutorados. Um na Sussex University na Inglaterra entre 1988 e 1990 com bolsa do Conselho Nacional de Desenvolvimento Científico e Tecnológico - CNPq, período no qual desenvolveu projeto de pesquisa sobre "Mecanismos de Cura" e atuou como Professor Visitante. O outro foi um estágio em nível pós-doutorado realizado na Shrodells Psychiatric Unit do Watford General Hospital - WGH (Inglaterra), no período entre janeiro e março de 1979. Nesse contexto realizou "Curso e Vivência em uma Comunidade Terapêutica" sob coordenação dos Drs. Philip Evans e Mário Marrone.

\section{Atuação profissional}

O Prof. Jorge Ponciano Ribeiro iniciou suas atividades docentes em 1962, atuando como Professor Titular na Fundação Universidade Norte de Minas -FUNM. No período entre 1962 e 1968 ministrou as disciplinas de Psicologia da Educação, História da Filosofia e Filosofia-Problemas Metafísicos. Entre 1973 e 1975 o Professor exerceu o cargo de Diretor da Faculdade de Filosofia, Ciências e Letras da referida Instituição.

Em março de 1976 ingressa na UnB, instituição onde atuou como professor de graduação e pós-graduação, pesquisador e orientador de dissertações de mestrado e teses de doutorado. Contribuiu para a criação do serviço de Psicologia do Instituto, inicialmente denominado UEEP e posteriormente CAEP, onde atuou também como psicológico clínico e ofereceu estágios, contribuindo para a formação clínica dos alunos. O Prof. Ponciano se tornou Professor Titular da Universidade de Brasília em julho de 1991. Aposentou-se em 31 de dezembro de 1992. Após sua aposentadoria, contribuiu ainda com o Instituto de Psicologia e com a pós-graduação como Pesquisador Associado Sênior. Permanece como professor credenciado junto ao Programa de Pós-Graduação do Instituto de Psicologia.

Ao longo de sua trajetória, o Prof. Jorge Ponciano contribuiu para difusão e a formação de profissionais nas áreas de psicoterapia de grupo e Gestalt Terapia, ministrando cursos de extensão em diversas instituições de ensino do país. Contribuiu também para a formação de profissionais na área da saúde atuando em locais como a Fundação Hospitalar do Distrito Federal - FHDF, no Curso de Aperfeiçoamento em Saúde Coletiva do CEDRHUS para mencionar apenas algumas dentre as instituições públicas e privadas com as quais colaborou.

Ainda na área da Gestalt Terapia, o Prof. Jorge Ponciano foi professor didata do Centro de Estudos em Gestalt Terapia de Brasília-CEGEST, entre 1980 e 1988. Teve e tem participação fundamental em outros centros formadores, como é o caso dos Institutos de Gestalt Terapia de Recife, Fortaleza, de Goiás dentre outros. Fundou em julho de 1996 o IGTB - Instituto de Gestalt Terapia de Brasília, do qual é o presidente.

No âmbito internacional, o Prof. Ponciano fez parte do corpo editorial da revista "International Journal of Therapeutic Communities -IJTC' (Inglaterra) e participou como membro da Group Analysis Society - GAS, também da Inglaterra. Participou e participa ainda de eventos científicos com cursos e apresentação de trabalhos em países da América Latina e Europa.

\section{Contribuição ao Instituto de Psicologia}

O Prof. Jorge Ponciano teve um papel fundamental na consolidação do Curso de Graduação em Psicologia, em especial a área da Psicologia Clínica, e na construção do Programa de Pós-Graduação em Psicologia do Instituto de Psicologia da Universidade de Brasília.

$\mathrm{Na}$ Graduação, o Prof. Jorge foi responsável pelas disciplinas de Psicologia da Religião; Aconselhamento Psicológico; Dinâmica de Grupo; Testes Projetivos; Psicopatologia; e Teorias e Técnicas Psicoterápicas. Ofereceu estágios supervisionados tendo como base a Gestalt Terapia e a Psicoterapia de Grupo e orientou diversos projetos de pesquisa.

Na Pós-graduação ministrou as disciplinas Processos Grupais e Psicologia Comunitária. O Prof. Jorge Ponciano desenvolveu projetos em torno de três linhas de pesquisa - Fatores de Cura, Psicologia da Religião e Processos Grupais. O Professor orientou 17 dissertações de mestrado e três teses de doutorado. Possui duas orientações de mestrado e uma orientação de doutorado em andamento.

O Prof. Jorge Ponciano Ribeiro exerceu o cargo de Vice-diretor do Instituto de Psicologia no ano de 1990. Em 1988, foi coordenador da UEEP, hoje CAEP - Centro de Atendimento e Estudos Psicológicos. Participou também de diversas comissões ao longo de sua vida acadêmica.

\section{Contribuição à área da Psicologia}

O Prof. Dr. Jorge Ponciano Ribeiro é sem dúvida um dos grandes nomes da Psicologia brasileira, e em especial na área da Psicologia Clínica, por sua contribuição em divulgar, construir conhecimentos e consolidar a formação de profissionais nas áreas da Psicoterapia de Grupo e na Gestalt Terapia. Sua contribuição na área da Psicologia da Religião é também fundamental. A produção bibliográfica do Professor é referência obrigatória nas áreas mencionadas; inclui: sete livros publicados como autor e um publicado como organizador, dois capítulos de livros e 10 artigos completos publicados em periódicos nacionais ou internacionais.

Vale ressaltar ainda a contribuição dada à Psicologia brasileira através da presença atuante junto aos Conselhos Regional e Federal de Psicologia e da participação na gestão dessas entidades. Foi presidente da Câmara de Ética do Conselho Federal de Psicologia entre 1986 e 1989 e atuou como conselheiro do Conselho Regional de Psicologia $-1^{\text {a }}$. Região de 1991 até o ano de 2000.

\section{Conclusão}

A trajetória acadêmica e profissional do Professor Jorge Ponciano Ribeiro, juntamente com seu papel na construção e consolidação dos Cursos de Graduação e Pós-graduação do Instituto de Psicologia, e com sua dedicação incansável à produção de conhecimento, divulgação e formação na área da Gestalt Terapia e da Psicologia Clínica em geral resultaram em uma valiosa contribuição para a consolidação da Psicologia brasileira. Sua atitude como humanista e profissional exemplar, o conjunto de sua obra e sua ativa participação no cenário da Psicologia brasileira nos dão a convicção do mais justo merecimento do reconhecimento institucional da Universidade de Brasília por meio da outorga do Título de Professor Emérito. 